\section{Drinking elicited by CNS injection of angiotensin in the rat*}

\author{
CAROL SUE WHITE \\ Memphis State University, Memphis, Tenn. 38111 \\ and \\ ROBERT A. LEVITT and SANDY BOYER
}

Southern Mlinois University, Carbondale, Ml. 62901

Limbic system sites from which drinking can be elicited by angiotensin are distributed similarly but not identically to cholinergic drinking sites in the rat. Furthermore, neither cholinergic nor adrenergic blocking agents depress drinking to angiotensin. However, water-deprived, cholinergically stimulated, and angiotensin-stimulated rats show similar sodium chloride preferences. Although the cholinergic and angiotensin systems seem independent, they may both produce a "true thirst."

Drinking has been elicited, in the rat, by injecting the kidney factor, angiotensin, or a cholinomimetic drug (carbachol) into hypothalamic or limbic system sites (Epstein, Fitzsimons, \& Simons, 1969; Fisher \& Coury, 1962; Giardina \& Fisher, 1971). Central injection of an anticholinergic drug, atropine, was found to block cholinergically induced drinking (Levitt \& Fisher, 1964).

Eserine, a cholinesterase inhibitor, was also found to produce drinking following central injection, and a $95 \%$ correlation was found between neural site sensitivity to carbachol and eserine. Furthermore, central injection of atropine blocked eserine-elicited drinking just as it blocked carbachol-elicited drinking (Levitt \& Boley, 1970). However, central atropine was found not to block drinking induced by angiotensin, suggesting that angiotensin induces drinking by a mechanism that may be independent of the cholinergic thirst system (Giardina \& Fisher, 1971).

Rats made thirsty by water deprivation or central carbachol preferred a dilute sodium chloride solution $(0.9 \%)$ to water but avoided more concentrated solutions $(2 \%$ or $4 \%$ ). These data suggest that, even though the mechanism responsible for drinking following central carbachol injection may not be identical to that responsible for drinking following water deprivation, a true "thirst" may be produced (Stellar, Hyman, \& Samet, 1954; Stricker \& Miller, 1968).

We now report the results of three experiments which investigated the angiotensin induction of drinking. In the first, we compared the location of carbachol- and angiotensin-responsive neural sites (correlation study). In the second, we attempted to block

*Supported by USPHS-NIMH Grant MH-14381. drinking to angiotensin with central injection of cholinergic and adrenergic antagonists (blockade study). In the third study, we investigated the sodium chloride preference of angiotensin-injected rats (salt-preference study). METHOD

Data presented were obtained from 149 adult male Long-Evans strain rats. One hundred and twenty-one rats were used in the correlation study, and 17 of these 121 were used in the blockade study; a different group of 28 rats was used in the salt-preference study.

Animals were implanted (under pentobarbital anesthesia) using common stereotaxic techniques. A single cannula implant (23-ga) in each animal was aimed at one of three structures: lateral septal nucleus (ATR), or lateral hypothalamic area (LHA).

The drugs and doses administered were angiotensin, 1.0 microgram; carbachol, 2.5 microgram; atropine sulfate, 2.5 microgram; scopolamine hydrobromide, 2.5 microgram; and phentolamine mesylate, 13 microgram. Each drug dose was dissolved in 1 microliter of sterile isotonic saline and delivered into the brain through the 23-ga cannula implant via a Hamilton syringe and a 30-ga needle.

Testing began 7 days after surgery, and tests were conducted at 5-7-day intervals. All drinking tests were $1 \mathrm{~h}$ the home cages, except that they contained a metered water bottle and food was not available.

Correlation Study

Each animal (113) was stimulated twice through the implant at weekly intervals, in a counterbalanced order, with angiotensin and carbachol. The stimulations were aimed for the center of the structure supposedly implanted. Blockade Study

The blocking agent (atropine, ( $\mathrm{LSN}$ ), anterior thalamic region long and performed in cages similar to scopolamine or phentolamine) was injected into an angiotensin-positive drinking site followed within 2 min by an angiotensin injection into the same site. Seventeen animals from the previous study were tested with all three blockers in a counterbalanced order (at 7-day intervals). For comparative purposes, these 17 animals (which were also positive to carbachol at this site) were also tested with atropine and scopolamine, followed by carbachol.

Salt Preference Study

Rats were first tested for the drinking of distilled water following angiotensin injection into the brain. When a site was found at which the animal drank at least $4.0 \mathrm{ml}$ during a 1-h test, testing with salt solutions began. On the next 3 test days, at 7-day intervals, the animal was tested for $1 \mathrm{~h}$ following angiotensin injection with $0.9 \%, 2.0 \%$, or $4.0 \%$ sodium chloride solution in a random sequence. Only one bottle was on the test cage for the test, containing one of the three salt solutions. However, for the week preceding the test, the animal had two bottles mounted on its home cage, one containing distilled water and the other the upcoming test solution. This was done to familiarize the animal with the test solutions. Following the tests with the three salt solutions, the animal was again tested with distilled water. Only if the animal still drank to angiotensin (at least $4.0 \mathrm{ml}$ ) was the data used. The mean of drinking on this trial and on the distilled water trial that preceded the salt solutions was computed to obtain a distilled water preference score.

Histological sections, permitting verification of stimulation sites, were obtained for all animals.

\section{RESULTS}

Correlation Study

Of the 121 sites (one per $S$ ) tested with both angiotensin and carbachol, drinking (at least $4.0 \mathrm{ml}$ ) to both drugs occurred at 76 , to neither at 20 , only to angiotensin at 12 , and only to carbachol at 13 . Therefore, $80 \%$ of the tested sites showed a consistency of response to both agents.

A number of stimulation sites were found to be improperly located. Several were in the dorsal fornix, corpus callosum, and lateral ventricle, as well as LSN, ATR, and LHA. Drinking to both agents was found for probes centered in all the sites listed above. Volume drunk was very similar for both drugs in all structures. Considering all 121 placements, water intake averaged $6.6 \mathrm{ml}$ following angiotensin and $6.5 \mathrm{ml}$ following carbachol. However, when the volume of intake to the two agents was correlated, only a small $(+0.22)$ but significant $(\mathrm{p}<.02)$ correlation was 
obtained. It may be of some importance that the highest correlations were found for probes located in fibers (dorsal fornix: +0.84 , $\mathrm{p}<.01$; corpus callosum: +0.70 , $\mathbf{p}<.05)$.

Latency of the drinking effect (time from drug injection until drinking began) was obtained for the 76 sites positive to both drugs. Latency scores for the two drugs were not significantly correlated. However, latency for angiotensin drinking (134 sec) was significantly less than latency for carbachol drinking (309 sec; $p<.01$ ).

\section{Blockade Study}

No significant difference in blockade due to stimulation site was found (LSN, ATR, and LHA were all tested). Therefore, the data were collapsed across structures. Seventeen animals received the treatments in a random sequence. The treatments and the associated water intake were: angiotensin $=8.6 \mathrm{ml}$; angiotensin plus atropine $=9.5 \mathrm{ml}$; angiotensin plus scopolamine $=10.0 \mathrm{ml}$; angiotensin plus phentolamine $=12.4 \mathrm{ml}$; carbachol $=8.0 \mathrm{ml}$; carbachol plus atropine $=2.9 \mathrm{ml}$; carbachol plus scopolamine $=2.2 \mathrm{ml}$. None of the blocking agents significantly affected the volume of water intake following angiotensin. Both cholinergic inhibitors significantly depressed carbachol-elicited drinking $(\mathrm{p}<.01)$. Salt Preference Study.

The amount of water intake differed across structures, being highest in the LSN-stimulated animals and lowest in the LHA animals. However, the effect of the salt solutions on water intake did not differ by stimulated structure. Therefore, the data were collapsed across structures. The 28 animals averaged $9.0 \mathrm{ml}$ of distilled water, $14 \mathrm{ml}$ of $0.9 \%$ sodium chloride, $6 \mathrm{ml}$ of $2.0 \%$ sodium chloride, and $1.0 \mathrm{ml}$ of $4.0 \%$ sodium chloride. This preference function is quite comparable to that obtained with water deprivation or cholinergic brain stimulation (Stellar, Hymen, \& Samet, 1954; Stricker \& Miller, 1968).

$$
\text { DISCUSSION }
$$

These experiments were attempts to evaluate the relationship of angiotensin-elicited drinking to the cholinergic thirst system and to natural thirst. It appears that there is a considerable similarity between the neural sites from which drinking is elicited by angiotensin and those from which drinking is elicited by carbachol. However, this overlap is less than that for successful carbachol and eserine sites (both cholinergic drugs) and may simply be a reflection of the small size of the rat brain and the limbic system distribution of both substrates. Furthermore, the failure of anticholinergic drugs to block angiotensin-drinking suggests that a cholinergic system is not importantly involved.

In contrast, the salt preference data suggest that animals stimulated to drink by angiotensin, carbachol, or water deprivation are under similar drive states.

\section{REFERENCES}

EPSTEIN, A. N., FITZSIMONS, J. T., \& SIMONS, B. J. Drinking caused by the intracranial injection of angiotensin into the rat. Journal of Physiology, 1969, 200. 98-100.

FISHER, A. E., \& COURY, J. N. Chemical tracing of a central neural circuit underlying the thirst drive, Science, 1962. $138,691-693$.

GIARDINA, A. R, \& FISHER, A. E. Effect of atropine on drinking induced by carbachol, angiotensin and isoproterenol. Physiology \& Behavior, 1971, 7, 653-655.

LEVITT, R. A., \& BOLEY, R. P. Drinking elicited by injection of eserine or carbachol into rat brain. Physiology \& Behavior, 1970, 5, 693-695.

LEVITT, R. A. \& FISHER, A. E Anticholinergic blockade of centrally induced thirst. Science, 1966, 154 , 520-522.

STELLAR, E., HYMEN, R., \& SAMET, $S$ Gastric factors controlling water- and salt-induced drinking. Journal of Comparative \& Physiological Psychology, $1954,47,220-226$.

STRICKER, E, M \& MILLER, N. E. Saline preference and body fluid analyses in rats after intrahypothalamic injections of carbachol. Physiology \& Behavior, 1968 , 3, 471-475. 